



\section{Hybrid E-Learning}

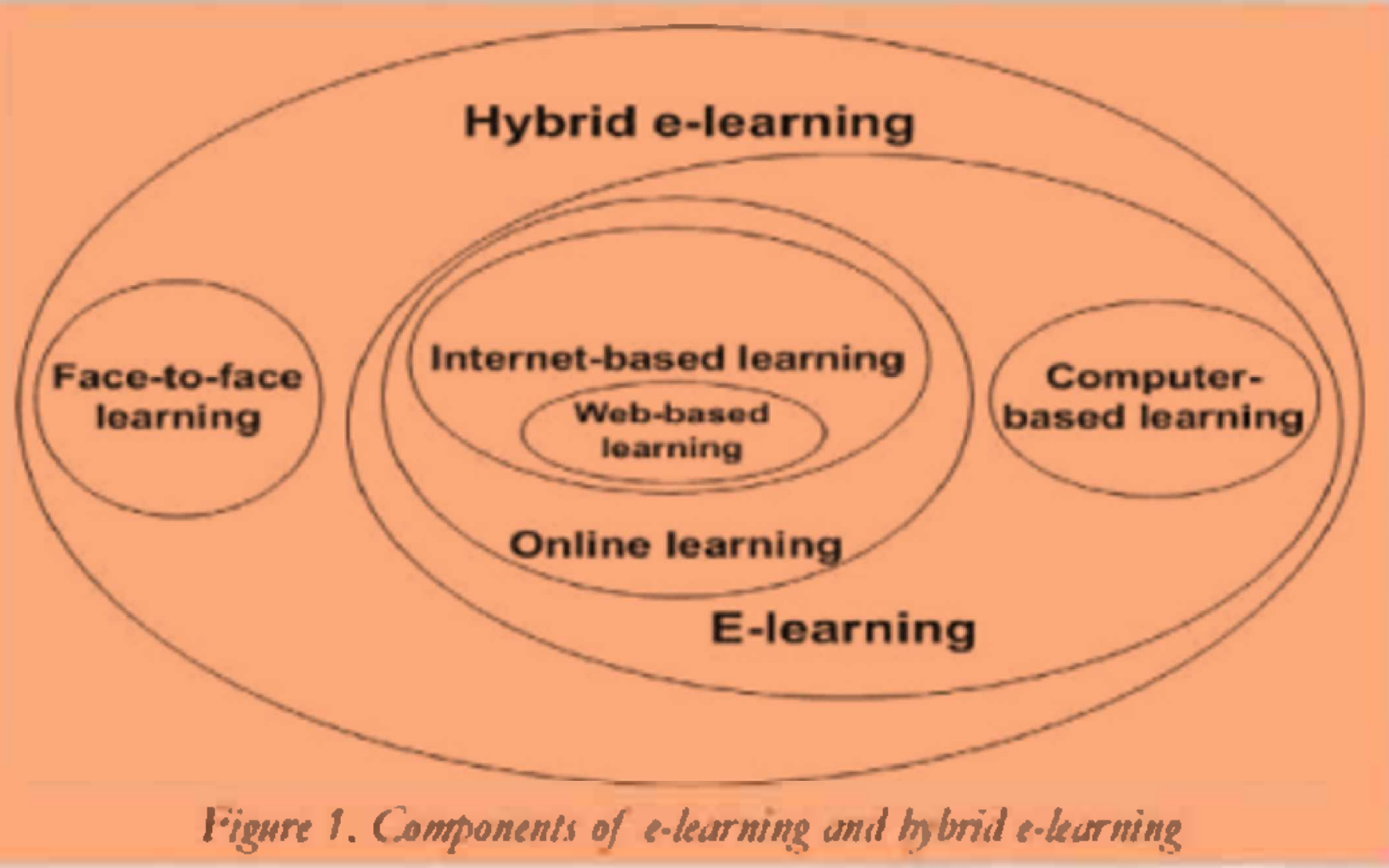




\section{How to Design E-Learning?}

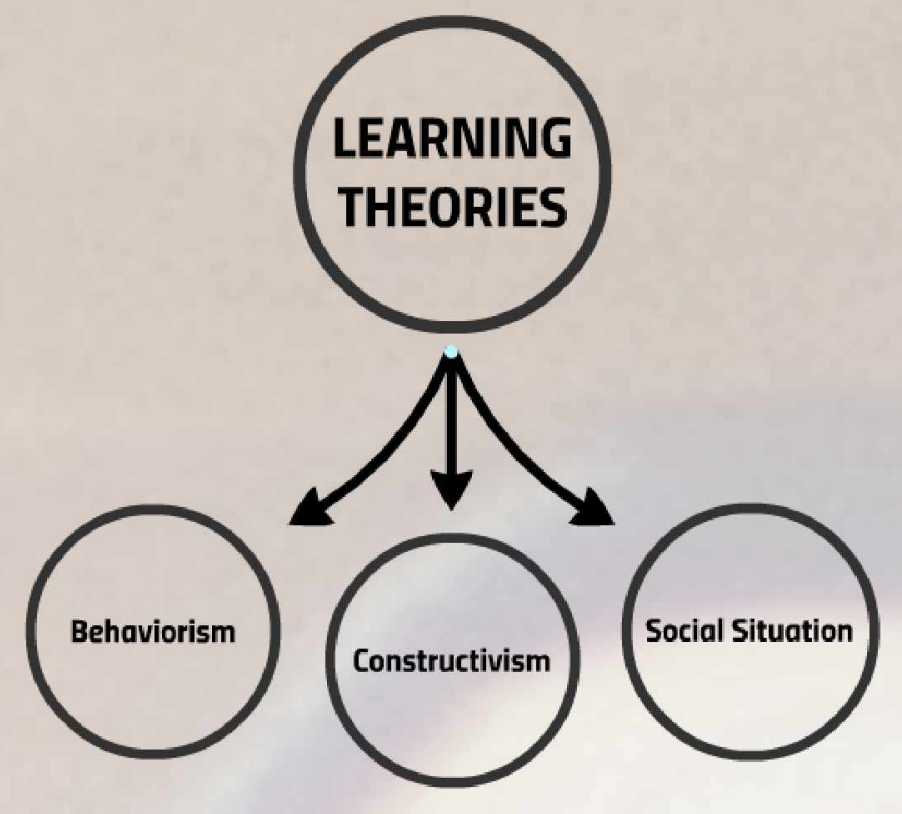




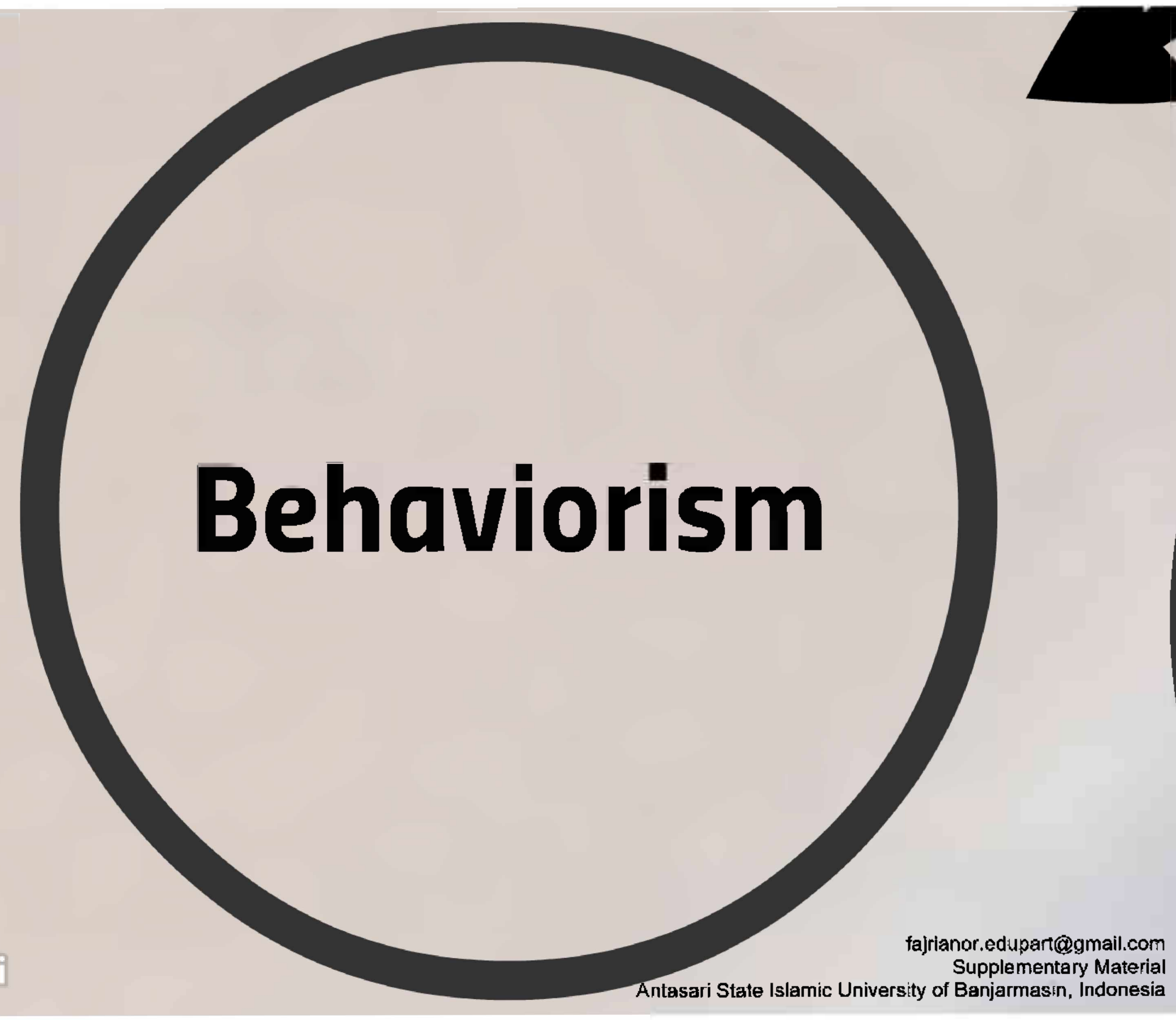




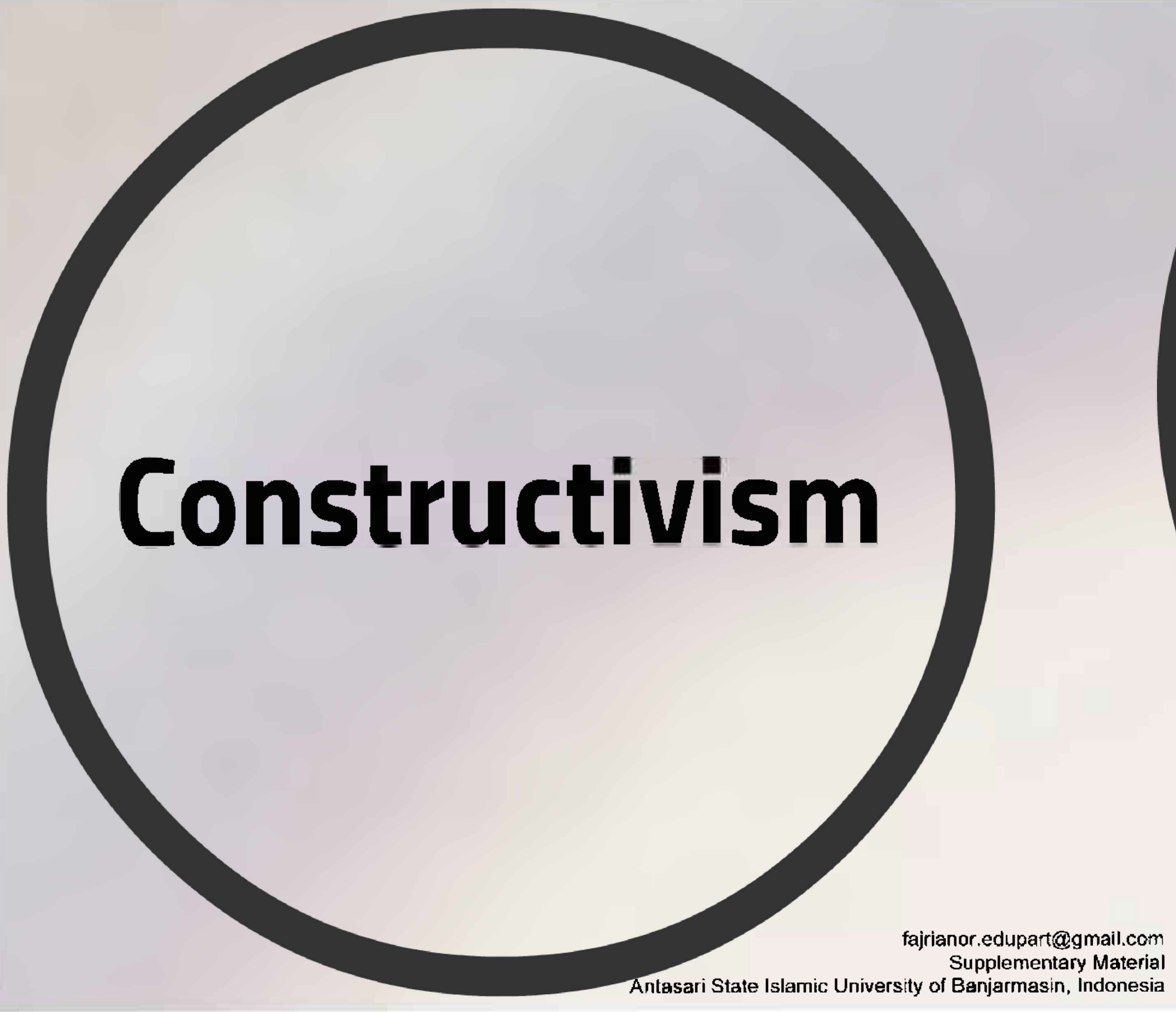




\section{LEARNING}

THEORIES
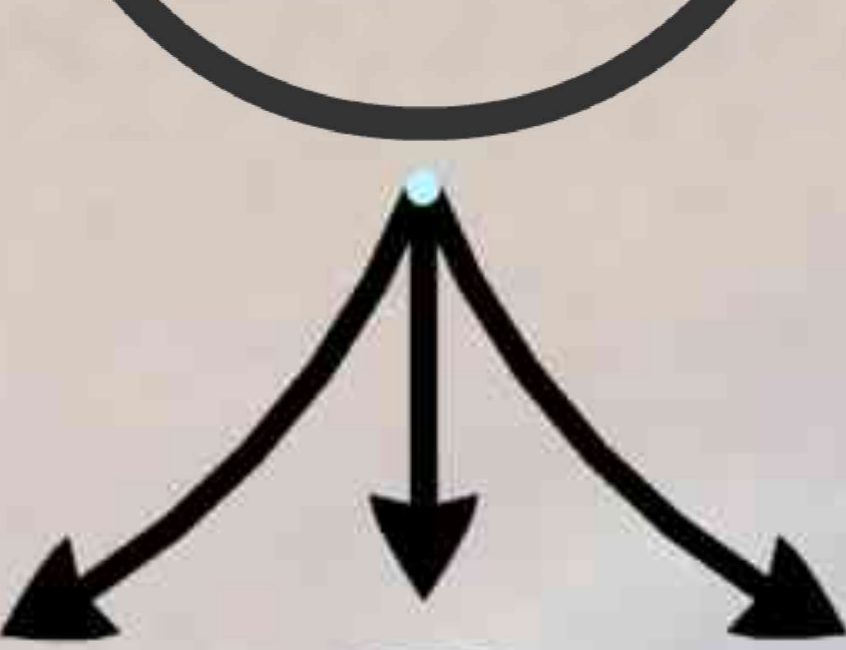

Behaviorism

Constructivism

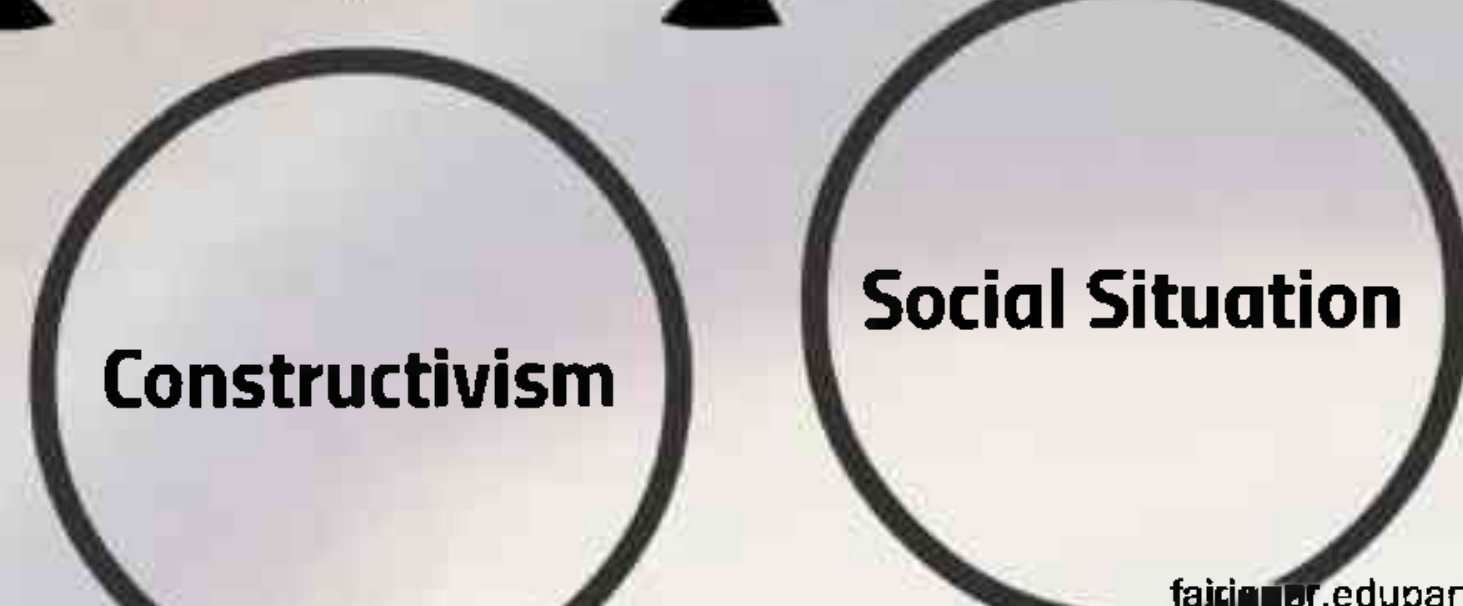

faiciolor.edupart@gmail.com 


\section{E-Learning Design}

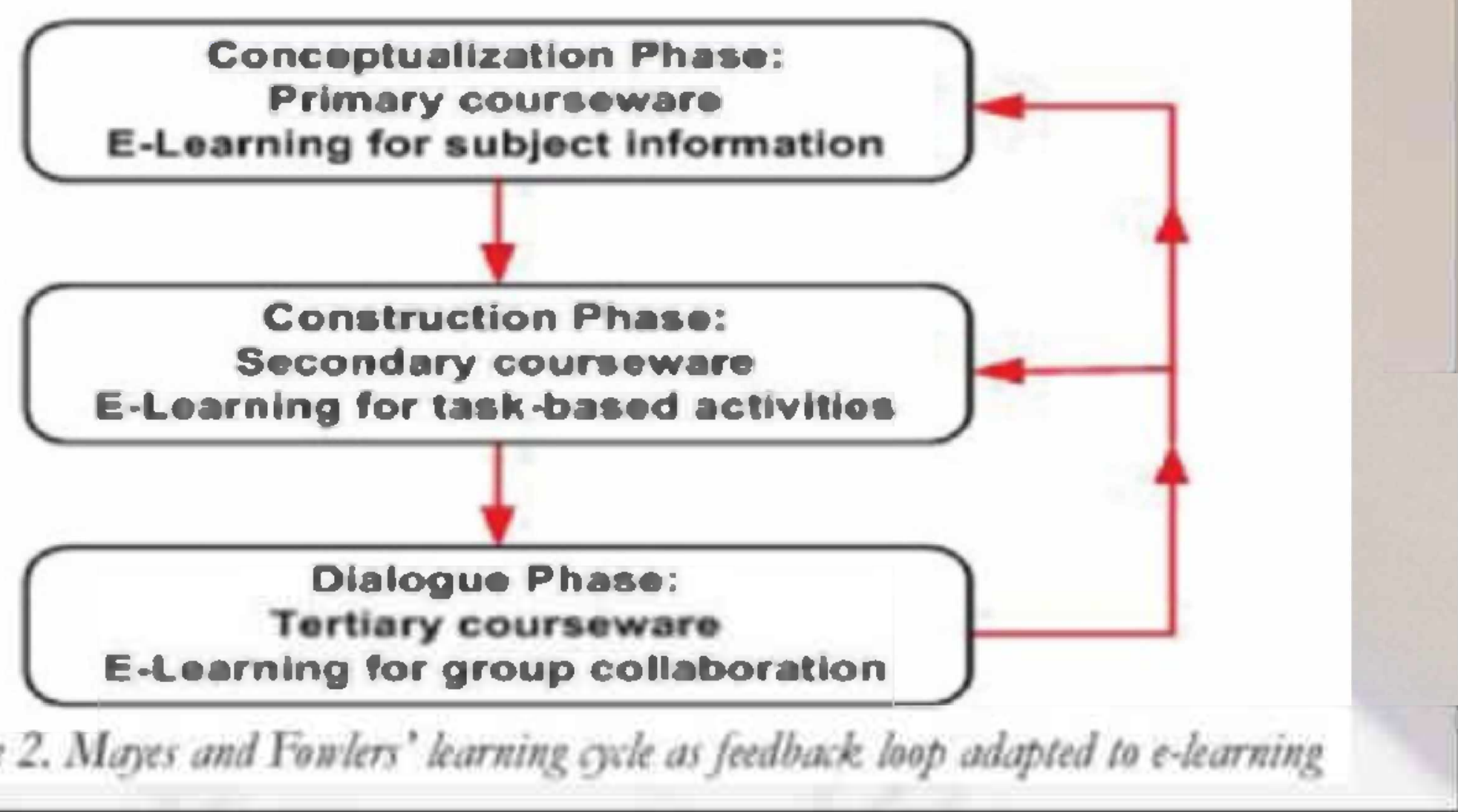

Figure 2. Moges and Fowlers' learning gre as feedback loop addapted to e-learning 


\section{E- Learning Implementation}

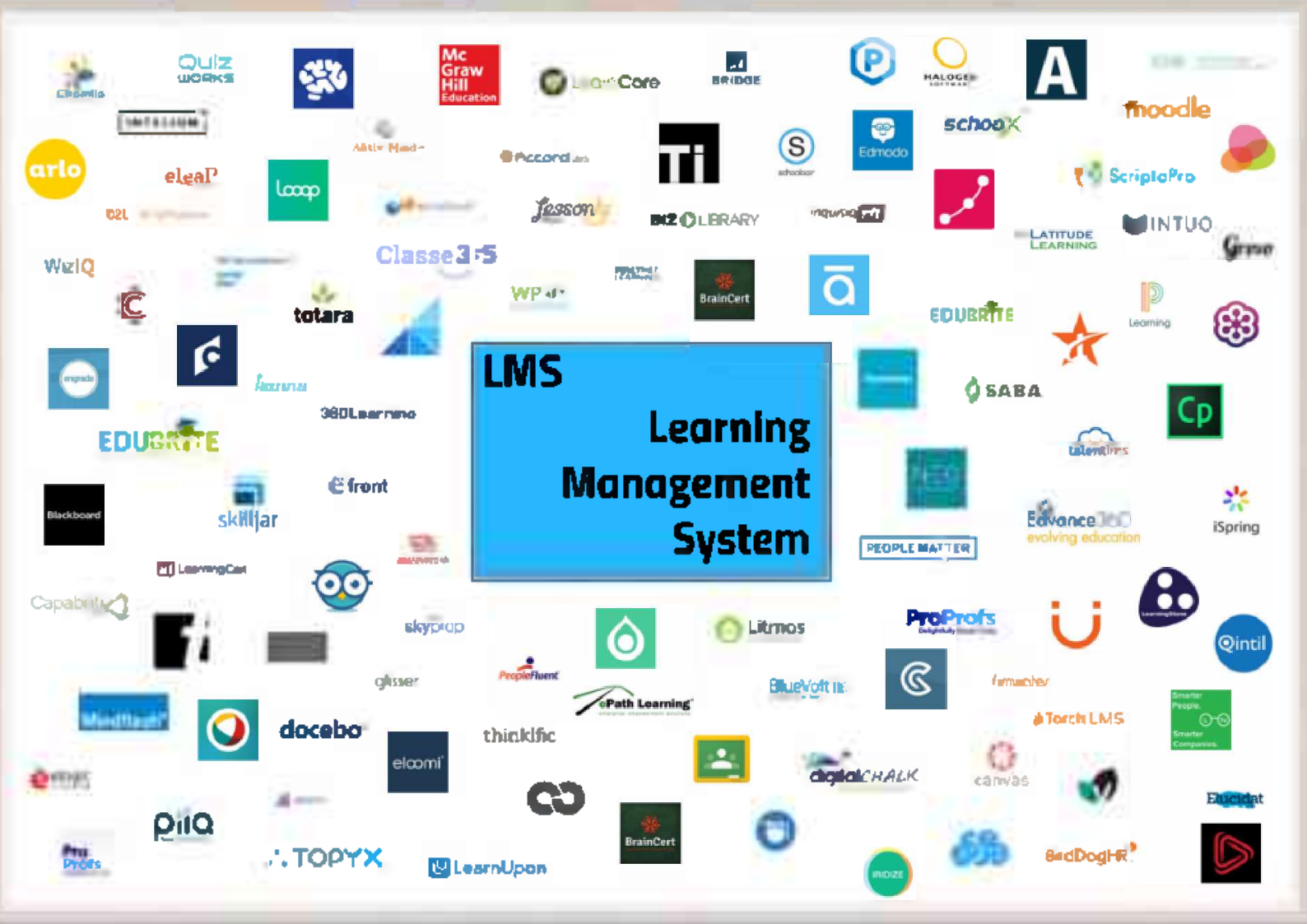




\section{How}

to

chose

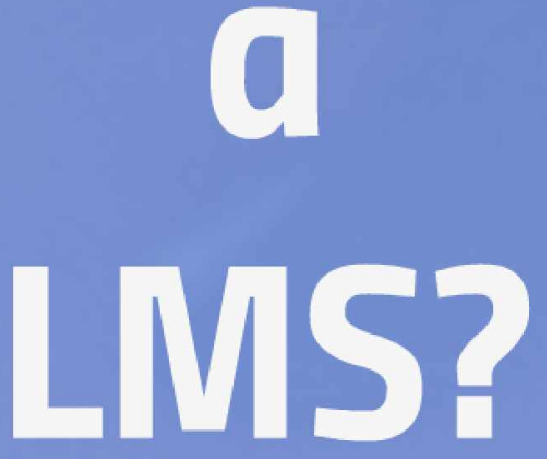




\section{Classroom \\ Transform Offline to Online Classroom}

O
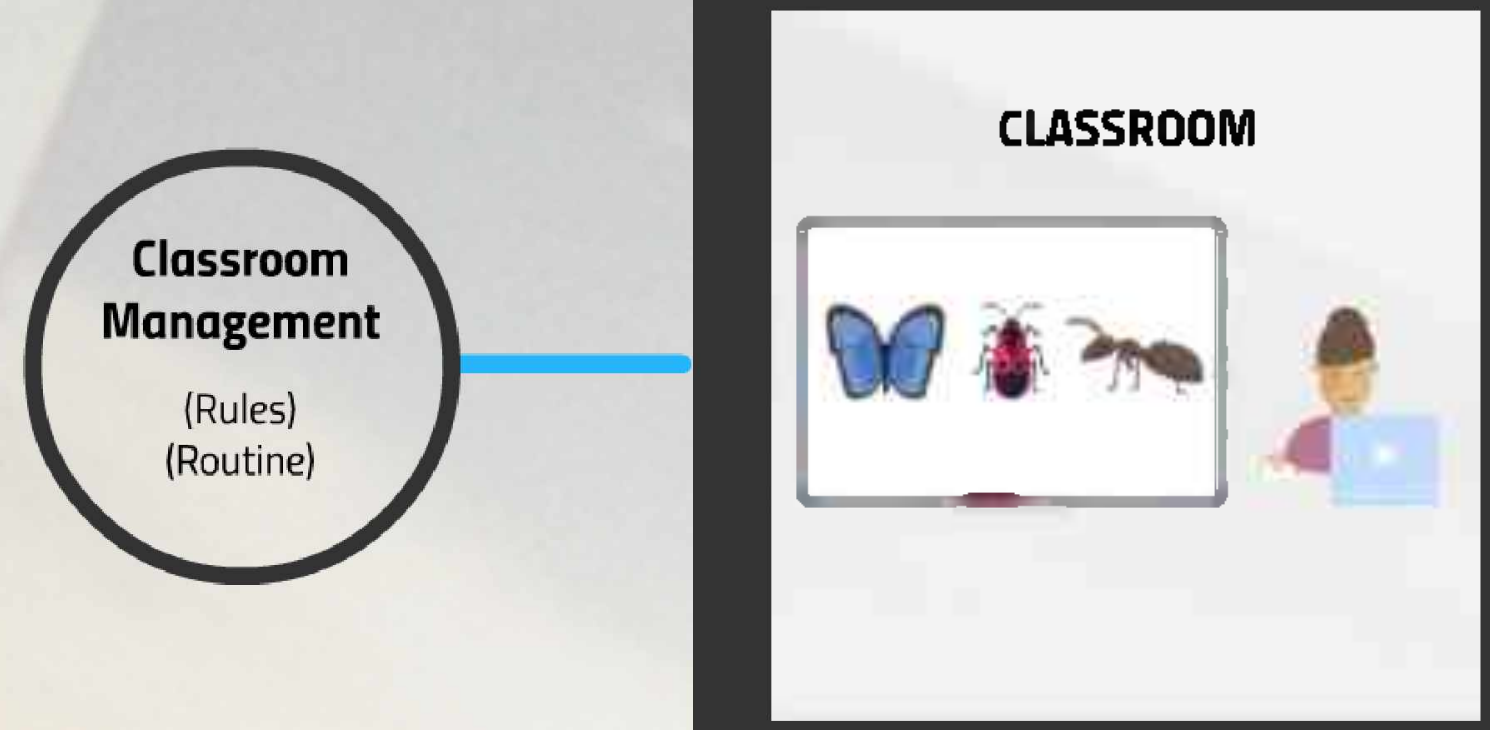

Classroom Organization

(Physical)

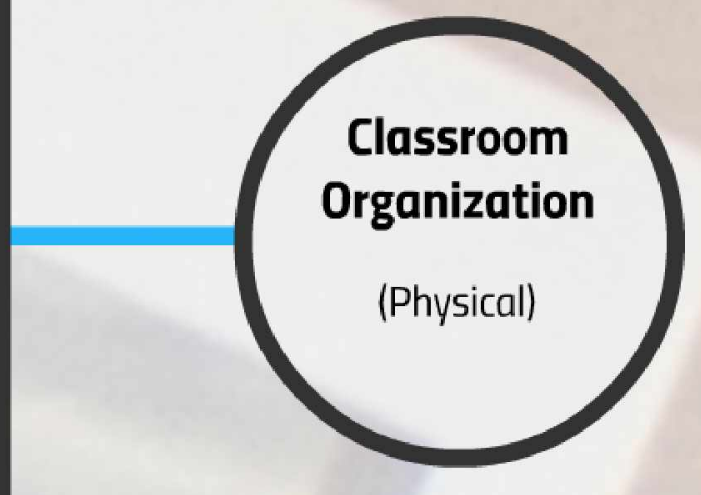





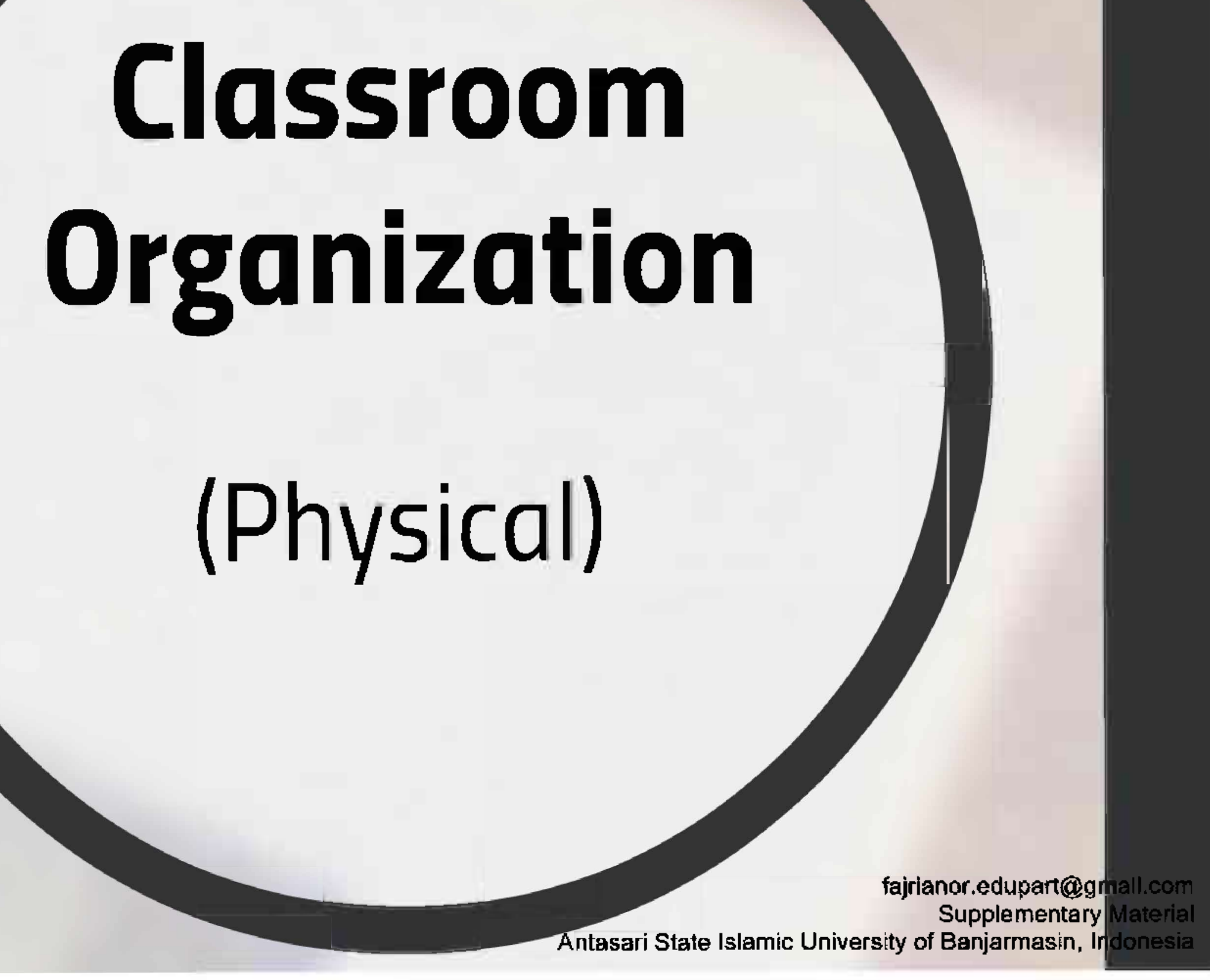




\section{Classroom \\ Transform Offline to Online Classroom}

\section{Classroom
Management}

(Rules)

(Routine)

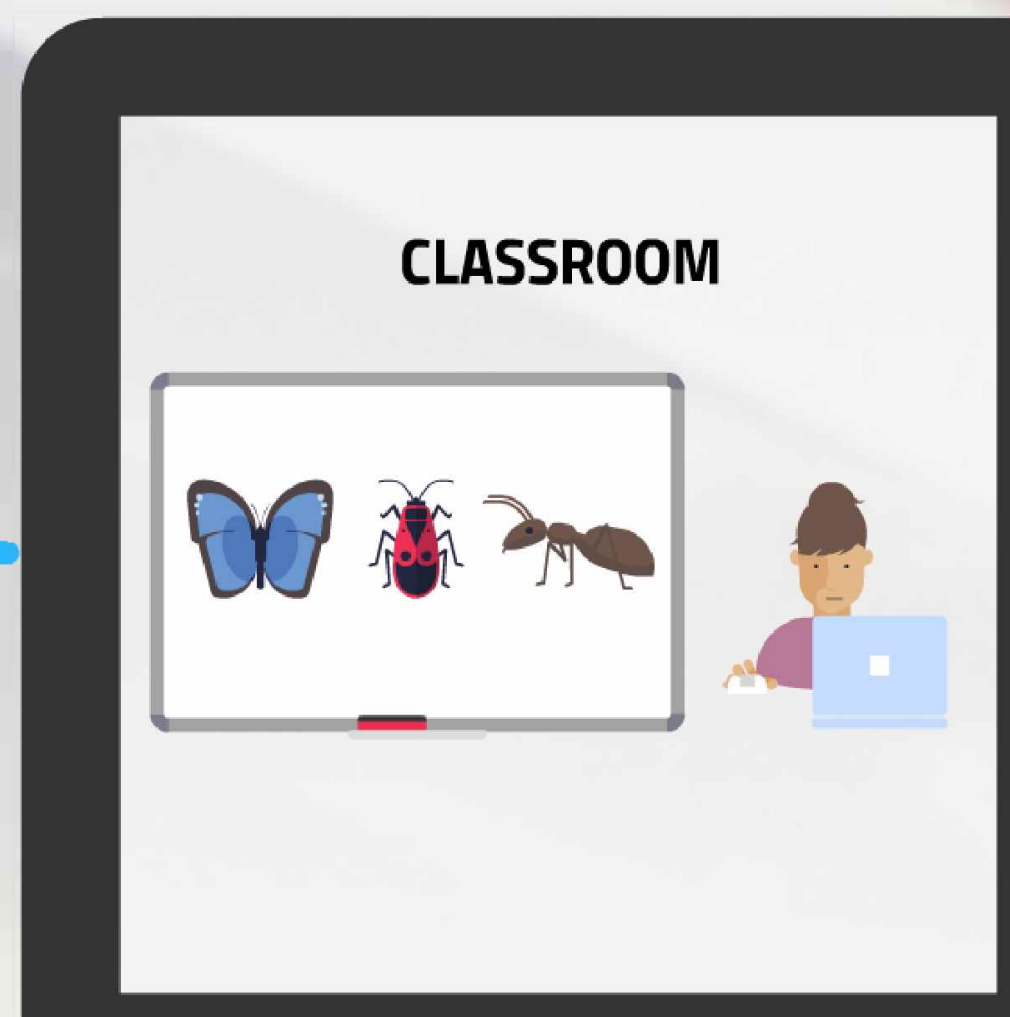

Classroom Organization

(Physical)

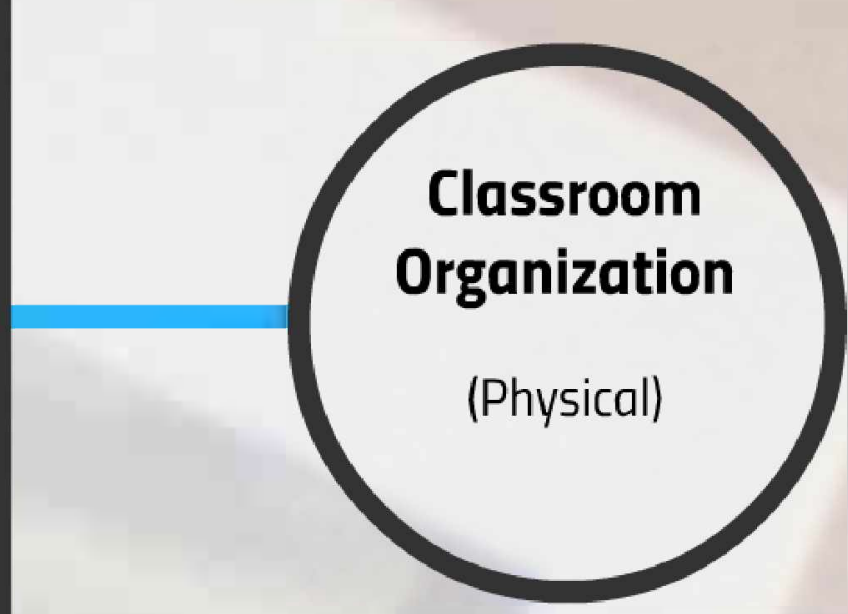




\section{LMS \\ VS \\ SOCIAL MEDIA}

edmodo Blackboard, froodle

$\boldsymbol{\Theta}$ schooloer canvas 1 absorb

\section{or}

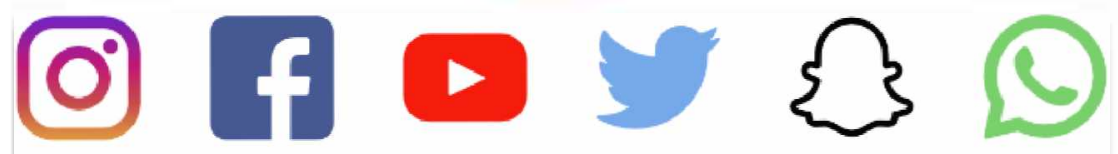

G+ in 1 (1) (1)

\& 5 P a 0

Which one? 


\section{CALL as Tutor or Tool}

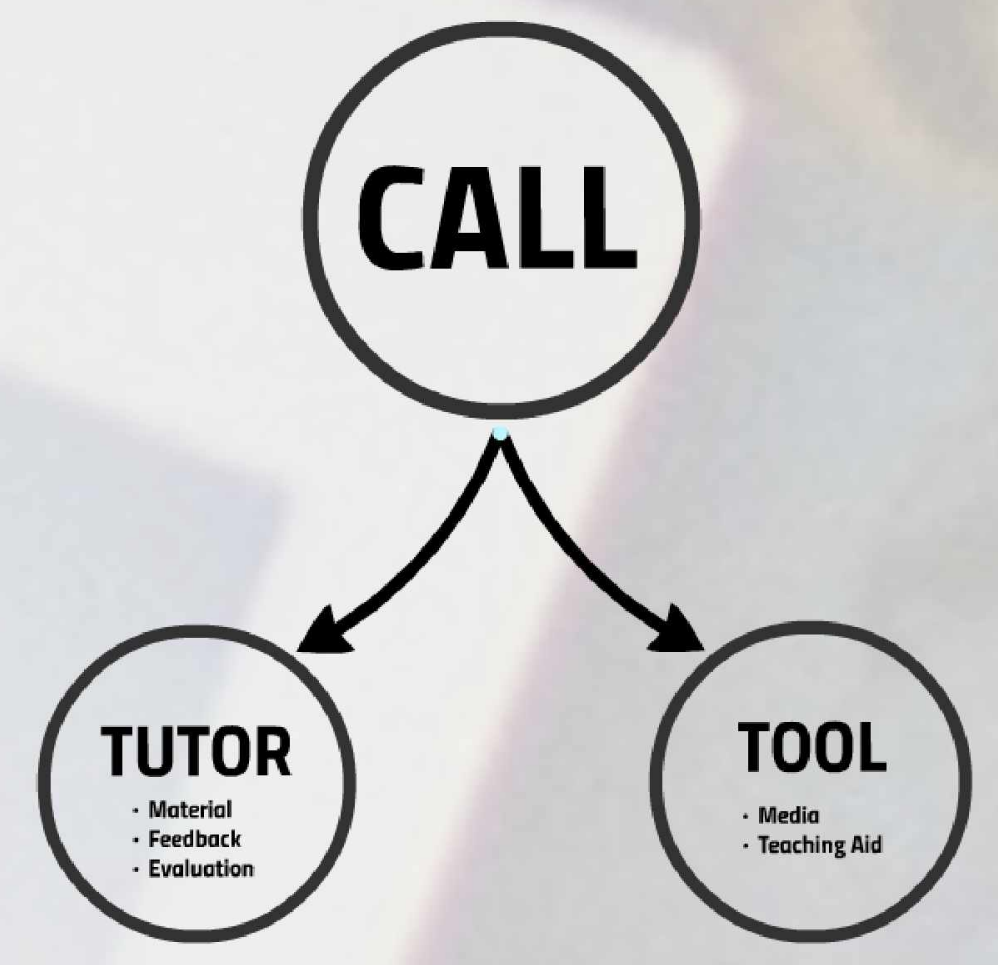





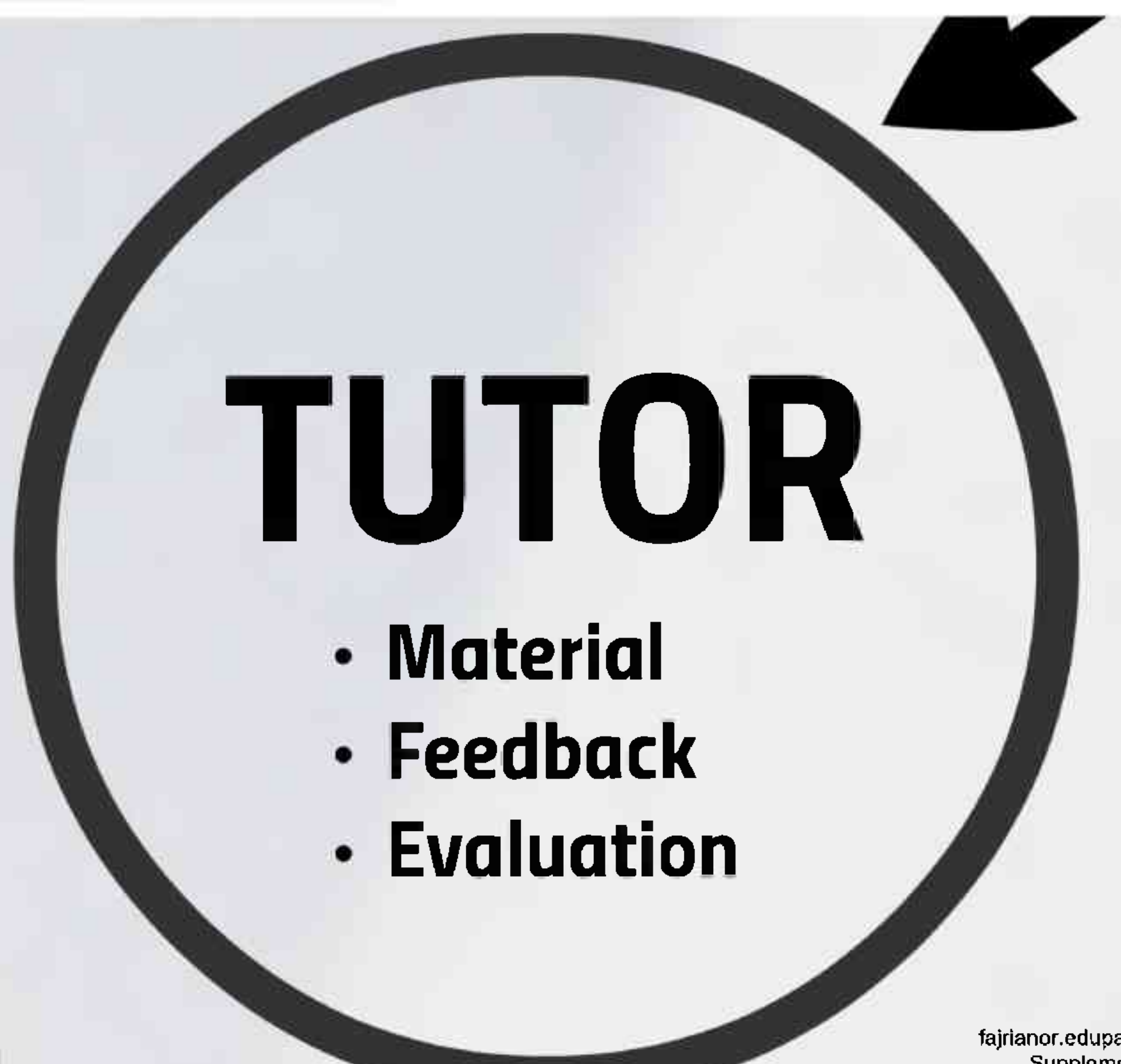

fajrianor.edupart@gmail.com Supplementary Material Antasari State Islamic University of Banjarmasin, Indonesia 



\section{CALL as Tutor or Tool}

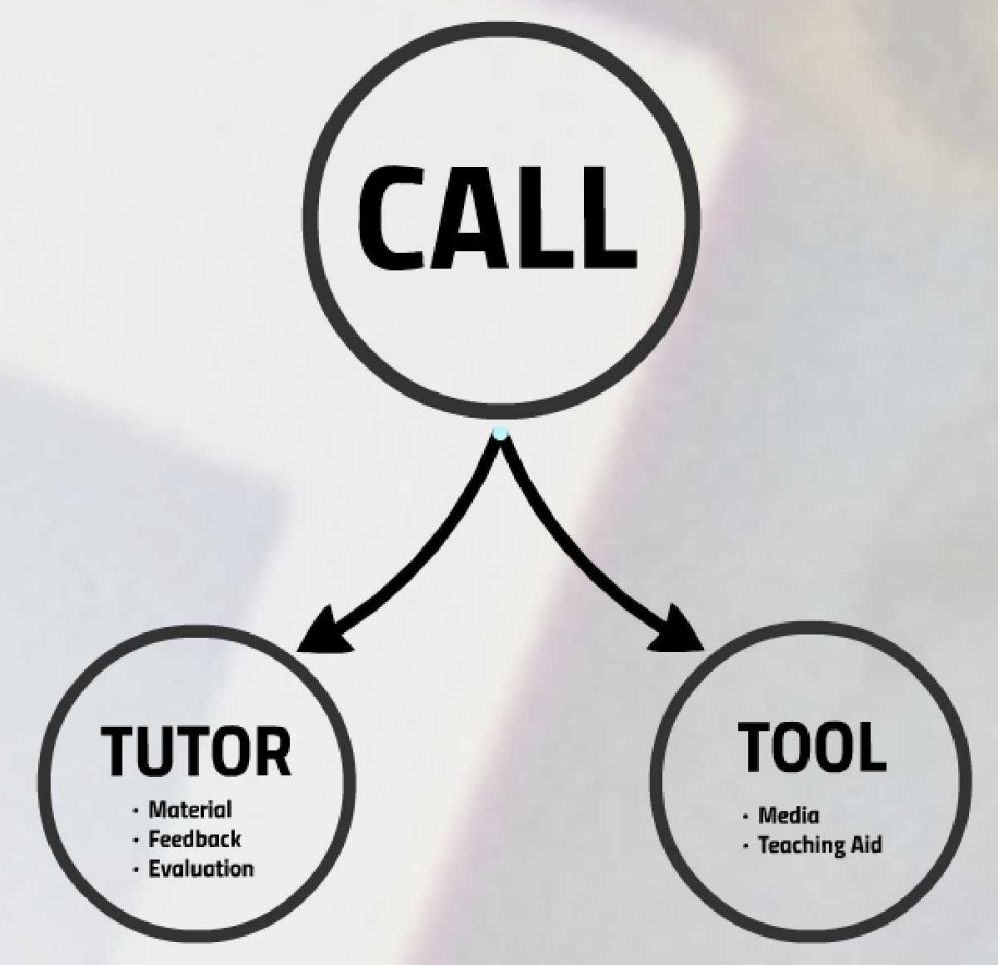




\section{References}

Buzzetto-More, N. A.(2007). Advanced Principles of Effective e-Learning. Santa Rosa, California: Informing Science Press. (pp. 27-58).

Levy, M. 2002. 'CALL by design: discourse, products and processes', ReCALL 14(1): 58-84

Levy, M., Blin, F.,Siskin, C. B., \& Taeuchi, 0. 2011.

WorldCALL International Perspectives on Compurter Assisted Language Learning. New York: Rouledge.

Mayes, J. T., \& Fowler, C. J. (1999). Learning Technology and Usability; a Framework for Understanding Couseware. Interacting with Computers, Volume 11, Issue 5, 485-497 
